\title{
Commentary Ontario's Efforts to Reduce Time Spent in Hospital Emergency Departments
}

\author{
Alan Hudson
}

The authors of this article are to be congratulated for analyzing key data, reiterating the major reasons for emergency department (ED) overcrowding and presenting their results in such a way that rational management decisions can be made that focus on solutions.

The work of Dr. Michael Schull - as referenced by the authors - and others has been instrumental in guiding efforts to reduce overcrowding and the time spent in EDs in Ontario. Over the past four years, the province completed a number of major reviews related to EDs, including the following:

- Improving Access to Emergency Services: A System Commitment. The Report of the Hospital Emergency Department and Ambulance Effectiveness Working Group (Schwartz 2005) - this 2005 review identified ways to address ambulance off-load delays in EDs

- Improving Access to Emergency Care: Addressing System Issues (Bell et al. 2006) - this 2006 review made evidencebased, practical recommendations to improve patient access to emergency care

In response to these reviews, in October 2007, both the premier and minister of health and long-term care expanded Ontario's Wait Times Strategy to include time spent in the ED. The Expert Panel on Emergency Departments - chaired by Dr. Schull - advised the Ontario government on reducing the time spent in the ED. Major initiatives include the following:

- Selected hospitals with high ED volumes and ED wait times pressures receive incentives to improve their performance through an innovative Pay-for-Results Program. Hospitals must reduce wait times for higheracuity patients (Canadian Triage and Acuity Scale [CTAS] levels 1-3), reduce the number of patients with extremely long waits (greater than 24 hours) and ensure that wait times for lower-acuity patients do not get worse. (Patients categorized as CTAS level 1 require resuscitation, level 2 are emergent, level 3 are urgent, level 4 are less urgent and level 5 are non-urgent.) Hospitals must also regularly track patient satisfaction and monitor quality of care.

- The Emergency Department Reporting System collects information from 128 hospital EDs in Ontario, with more than 20,000 ED visits a year. Hospitals submit information on their ED length of stay, ambulance off-load time, time to physician assessment in the ED, time to disposition decision and time to hospital admission.

- An ED Performance Improvement Program has been developed based on the results of three demonstration pilots to improve ED patient flow.

- Several new roles have been developed for nurses working in EDs: for example, (1) emergency medical service nurses, who are ED nurses, are dedicated to offloading ambulance patients safely and in a timely fashion so that ambulance crews can get back on the road quickly; and (2) nurse-led long-term care outreach teams now diagnose and treat clinical problems, as appropriate, in long-term care homes, avoiding unnecessary transfers to hospital EDs. 
- An Alternate Level of Care Plan has been developed with initiatives targeted at reducing the number of patients in hospital who no longer require the level of care provided by the facility.

- Projects have been put in place (e.g., chronic disease management, community and facility supports, etc.) to help control the "demand" for ED services.

The most significant development $-\mathrm{a}$ first in Canada and in North America - has been the announcement of Ontario targets for the time spent in EDs and public reporting of these wait times (Ministry of Health and Long-Term Care 2009). In February 2009, the Minister of Health and Long-term Care, David Caplan, announced targets for the length of time

\section{Programs from governments, professional associations and private sector organizations claim to mitigate risk by testing and certifying vendor products against requirements for usability, functionality and interoperability.}

Ontarians can be expected to wait in EDs for final treatment. The total time spent in the ED begins when a patient registers in the ED or initially sees a triage nurse (who assesses the level of urgency for treatment), and it ends when the patient leaves the ED and is discharged home or admitted to a hospital bed. It is expected that patients are receiving treatment during their time in the ED.

Ontario's targets are the following:

1. 9 out of 10 patients whose conditions are minor or uncomplicated and require less time for treatment, diagnosis or observation will spend no more than 4 hours within the ER from the time they arrive and register to the time their visit is complete and they are discharged.

2. 9 out of 10 patients with complex conditions that may require more time for treatment, diagnosis or admission to a hospital bed will spend no more a eight hours within the ER from the time they arrive and register to the time they leave the ER.

Ontario's data indicate the following for January 2009 (compared with an April 2008 baseline; Table 1):

- Nine of 10 people with complex conditions requiring more time for diagnosis, treatment or admission to a hospital bed spent up to 14.6 hours in the ED - this is well above the provincial access target of eight hours

- Nine of 10 people with minor or uncomplicated conditions requiring less time for diagnosis, treatment and observation spent up to 4.8 hours in the ED, which is slightly higher that the provincial access target of four hours; the province is making a determined effort to hit the fourhour target time within the next two years

A closer analysis of the data highlights the fact that the fundamental problem in ED wait times in Ontario is similar to that in the Alberta experience. In January 2009, Ontario patients with complex conditions spent up to 40.0

Table 1. Time spent in the ED from patient registration to patient discharge home or admission to hospital

\begin{tabular}{|l|c|c|c|c|c|c|}
\hline Type of ED Visit & $\begin{array}{c}\text { No. of ED } \\
\text { Visits }\end{array}$ & $\begin{array}{c}\text { Baseline } \\
\text { Wait (hours) } \\
\text { (April 2008) }\end{array}$ & $\begin{array}{c}\text { Current } \\
\text { Wait (hours) } \\
\text { (Jan 2009) }\end{array}$ & $\begin{array}{c}\text { Access } \\
\text { Target }\end{array}$ & $\begin{array}{c}\text { Completed } \\
\text { within Target* } \\
\text { (\%) }\end{array}$ & $\begin{array}{c}\text { Current vs. } \\
\text { Baseline } \\
\text { Change (hours) }\end{array}$ \\
\hline $\begin{array}{l}\text { Complex conditions requiring } \\
\text { more time for diagnosis, } \\
\text { treatment or admission to a } \\
\text { hospital bed }\end{array}$ & 230,593 & 13.9 & 14.6 & 8 & 79 & +0.7 \\
\hline $\begin{array}{l}\text { Minor or uncomplicated } \\
\text { conditions requiring less time } \\
\text { for diagnosis, treatment and } \\
\text { observation }\end{array}$ & 155,199 & 4.8 & 4.8 & 4 & 84 & 0 \\
\hline Totals & 385,792 & 9.4 & 9.8 & & & \\
\hline
\end{tabular}

$\mathrm{ED}=$ emergency department

*The target is defined as nine out of 10 patients who spent no more time in the ER than the access target. Data is from April 2008 (baseline) to January 2009 ).

Source: Emergency Department Reporting System. 
Table 2. Time spent in the ED by patients with complex conditions*

\begin{tabular}{|l|c|c|c|c|c|c|}
\hline Patient Status & ED Visits & $\begin{array}{c}\text { Baseline } \\
\text { Wait (hours) } \\
\text { (April 2008) }\end{array}$ & $\begin{array}{c}\text { Current } \\
\text { Wait (hours) } \\
\text { (Jan 2009) }\end{array}$ & $\begin{array}{c}\text { Access } \\
\text { Target }\end{array}$ & $\begin{array}{c}\text { Completed } \\
\text { within Target } \\
\text { (\%) }\end{array}$ & $\begin{array}{c}\text { Current vs. } \\
\text { Baseline } \\
\text { Change (hours) }\end{array}$ \\
\hline Admitted to hospital & 42,664 & 35.9 & 40.0 & 8 & 36 & +4.1 \\
\hline Not admitted to hospital & 187,929 & 8.5 & 8.4 & & 89 & -0.1 \\
\hline Totals & 230,593 & 13.9 & 14.6 & & 79 & +0.7 \\
\hline
\end{tabular}

$\mathrm{ED}=$ emergency department

* Conditions requiring more time for diagnosis, treatment or admission to a hospital bed.

The target is defined as nine out of 10 patients who spent no more time in the ER than the 8 hour access target. Data is from April 2008 (baseline) to January 2009 )

Source: Emergency Department Reporting System.

hours in the ED if they were admitted to hospital; this is well above the eight-hour access target. In contrast, patients with complex conditions who did not need to be admitted to hospitals spent up to 8.4 hours in the ED, which is close to the eight-hour access target (Table 2).

Patients are boarding in the ED because there are no available acute care beds. In April 2009, Ontario hospitals estimated that about $18 \%$ of acute care beds were occupied by alternative level of care (ALC) patients, who should not

\section{Certification programs were found to} facilitate GP systems adoption in two ways. First, they regulate GP systems markets by pre-testing vendor products against standards. Second, they often provide financial, technical and peer-to-peer support to GPs.

be there (Ontario Hospital Association 2009). (These are self-reported survey data; Ontario is currently implementing a standard provincial ALC definition that will capture near real-time ALC data in 92 acute care and 21 post-acute care hospitals by March 31, 2011.)

The crux of the ED issue is that community services - such as home care, long-term care and other services - need to be organized and financed in such a manner that they "pull" ALC patients out of the acute care setting. In turn, this will free up acute care beds for patients waiting in the ED to be hospitalized. In Ontario, Local Health Integration Networks (LHINs) are responsible for organizing community services and meeting LHIN ALC-reduction targets as part of their accountability agreements with the ministry. Under the LHINs, two points of accountability must be closely integrated if there is any hope of reducing ED wait times: (1) hospitals boards are responsible for ED-specific initiatives within the hospital, and (2) community agency boards are responsible for community-based services that help address ED waits.

Fundamentally, Bullard et al.'s article on the situation in Alberta illustrates the problem. Ontario is making efforts to act on the solutions.

\section{References}

Bell, R., J. Willett and J. Oliver, an Expert Working Group reporting to the Physician Hospital Care Committee, a tripartite committee of the Ontario Hospital Association, the Ontario Medical Association and the Ontario Ministry of Health and Long-Term Care. 2006. Improving Access to Emergency Care: Addressing System Issues. Toronto, ON: Ontario Hospital Association, Ontario Medical Association and Ontario Ministry of Health and Long-Term Care.

Ministry of Health and Long-Term Care. 2009. Ontario Wait Times. Toronto, ON: Author. <http://www.ontariowaittimes.com>

Ontario Hospital Association. 2009. ALC Survey Results. Toronto, ON: Author.

Schwartz, B. 2005. Improving Access to Emergency Services: A System Commitment. The Report of the Hospital Emergency Department and Ambulance Effectiveness Working Group. Toronto, ON: Minister of Health and Long-Term Care.

\section{About the Author}

Alan Hudson, OC, MBChB, FRCS(C), FRCS(Ed), is the lead of access to services/wait times for the Health Results Team, Ministry of Health and Long-Term Care, Toronto, Ontario. 